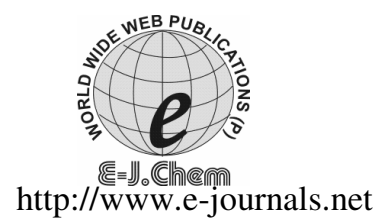

\title{
A Sensitive Validated Spectrophotometric Method for the Determination of Flucloxacillin Sodium
}

\author{
R. SINGH GUJRAL ${ }^{*}$, S MANIRUL HAQUE and P SHANKER \\ *Vardhman Chemtech Ltd, Nimbua, Dera Bassi, Mohali (Punjab), India. \\ gujral@vardhmanchemtech.com
}

Received 3 June 2009; Accepted 1 August 2009

\begin{abstract}
A simple and sensitive spectrophotometric method has been proposed for the determination of flucloxacillin sodium. The determination method is based on charge transfer complexation reaction of the drug with iodine in methanol-dichloromethane medium. The absorbance was measured at $362 \mathrm{~nm}$ against the reagent blank. Under optimized experimental conditions, Beer's law is obeyed in the concentration ranges $1-9 \mu \mathrm{g} / \mathrm{mL}$ for flucloxacillin. The method was validated for specificity, linearity, precision, accuracy. The degree of linearity of the calibration curves, the percent recoveries, limit of detection and quantitation for the spectrophotometric method were determined. No interferences could be observed from the additives commonly present in the pharmaceutical formulations. The method was successfully applied for in vitro determination of human urine samples with low RSD value. This is simple, specific, accurate and sensitive spectrophotometric method.
\end{abstract}

Keywords: Flucloxacillin, UV, Spectrophotometry method, Validation.

\section{Introduction}

Flucloxacillin, [3-(2-chloro-6-fluorophenyl)-5-methylisoxazol-4-yl] carbonyl] amino]-3,3dimethyl-7-oxo-4-thia-1- azabicyclo [3. 2.0] heptane-2-carboxylate] are the penicillinaseresistant penicillins. It is used as an antibiotic. Antibiotics are used not only in medicine but also in the food industry for food preservation, processing, and transportation, right down to the illegal introduction of antibiotics, for example, into dairy products in order to decrease the total number of microbes. The main channels for contaminating food with antibiotics are the use of antibiotics as veterinary drugs and as fodder additives.

Flucloxacillin is a narrow spectrum beta-lactam antibiotic of the penicillin class. It is used to treat infections caused by susceptible gram positive bacteria. Unlike other penicillins, flucloxacillin has activity against beta-lactamase producing organisms such as staphylococcus aureus as it is beta-lactamse stable. It inhibits cross-linkage between the linear peptidoglycon polymer chains that make up a major component of the cell wall of gram positive bacteria. 
Flucloxacillin is insensitive to $\beta$-lactamase (also known as penicillinase) enzyme secreted by many penicillin resistant bacteria. The presence of the isoxazolyl group on the side chain of the penicillin nucleus facilitates the $\beta$-lactamase resistance, since they are relatively intolerant of the side chain steric hindrance. Thus it is able to bind to penicillin binding proteins (PBPs) and inhibit peptidoglycon crosslinking, but is not bond by or inactivated by $\beta$-lactamases. It is more acid-stable than much other penicillin and can be given orally in addition to parenteral routes. Common adverse drug reactions (ADRs) associated with the use of flucloxacillin include: diarrhea, nausea, rash, urtcaria, pain and inflammation at injection site, superinfection (including candidiasis), allergy and transient increases in liver enzymes and bilirubin.

It is more fully absorbed and so gives higher blood levels. Also it is strongly protein bond and used for benzyl penicillin-resistant staphylococcal infections with an orally or I.M. dose of $250 \mathrm{mg} 6$ hourly $^{1}$. The literature presents liquid chromatographic ${ }^{2}$ and spectrophotometirc methods ${ }^{2-4}$ for the determinations of flucloxacillin.

The method is based on charge transfer complexation reaction of flucloxacillin and iodine. The absorbance was measured at $362 \mathrm{~nm}$ against the reagent blank. The method was successfully applied in bulk and in human urine samples.

\section{Experimental}

Spectral runs were made on UV $3000^{+}$UV-Vis spectrophotometer (LABINDIA ${ }^{\circledR}$, Mumbai, India) [Serial Number 17 - 1885 - $01-0016$ ] with $1 \mathrm{~cm}$ matched glass cell.

- Flucloxacillin Sodium (Vardhman Chemtech Ltd, Mohali, Punjab, India) used as a working standard.

- Iodine (RFCL Limited, New Delhi, India) was prepared as $0.1 \%$ solution in dichloromethane.

- Sodium carbonate was purchased from Qualigens fine chemicals (Mumbai, India).

- Urine samples were obtained from healthy volunteers

- Carbonate buffer of pH 9.4 was prepared by dissolving $26.5 \mathrm{~g}$ sodium carbonate and $21.0 \mathrm{~g}$ sodium bicarbonate in $500 \mathrm{~mL}$ distilled water.

\section{Standard drug solutions}

A stock solution of flucloxacillin $(100 \mu \mathrm{g} / \mathrm{mL})$ was prepared by dissolving $10 \mathrm{mg}$ flucloxacillin in $100 \mathrm{~mL}$ volumetric flasks with methanol. The stock solution $(100 \mu \mathrm{g} / \mathrm{mL})$ was used to prepare the working solutions by suitable dilutions with methanol. The solutions were stable at least 15 days in room temperature.

\section{Procedure for determination of flucloxacillin sodium}

Into a series of $10 \mathrm{~mL}$ volumetric flasks, different volumes $(0.02-0.18 \mathrm{~mL})$ of standard flucloxacillin sodium $(0.5 \mu \mathrm{g} / \mathrm{mL})$ solution corresponding to $1.0-9.0 \mu \mathrm{g} / \mathrm{mL}$ were pipetted. $1.0 \mathrm{~mL}$ of $0.1 \%$ iodine was added in each flask at room temperature and diluted up to the mark with methanol. The reaction was allowed to proceed at room temperature and absorbance was measured as a function of time at $362 \mathrm{~nm}$ against reagent blank prepared simultaneously. The calibration curve was constructed by plotting the absorbance against the initial concentration of flucloxacillin.

\section{Procedure for determination of flucloxacillin in human urine samples}

Aliquot volumes of human urine samples were transferred into small separating funnel. $10 \mathrm{~mL}$ of carbonate buffer $\mathrm{pH}-9.4$ was added and solution was mixed well. The solution was then 
extracted with $2 \times 5 \mathrm{~mL}$ diethyl ether. The ether extract was collected and evaporated. The residue was dissolved in $20 \mathrm{~mL}$ distilled water and above general procedure was then followed. The amount of flucloxacillin was obtained from the calibration graphs or corresponding regression equation.

\section{Evaluation of bias}

The bias has been evaluated by means of point and interval hypothesis tests ${ }^{5-6}$. In interval hypothesis the proposed method is accepted when the true mean is within $\pm 2 \%$ of that of the reference method, i.e.

$$
\text { Which can be generalized to }
$$

Which can be generalized to $\theta_{\mathrm{L}}<\mu_{2} / \mu_{1}<\theta_{\mathrm{U}}$

Where, $\theta_{\mathrm{L}}$ and $\theta_{\mathrm{U}}$ are lower and upper acceptance limits, respectively. The limits of this confidence interval can be calculated using the following quadratic equation:

$$
\theta^{2}\left(\bar{x}_{1}^{2}-S_{p}{ }^{2} t_{t a b}^{2} / n_{1}\right)-2 \theta \cdot \bar{x}_{1} \bar{x}_{2}+\left(\bar{x}_{2}{ }^{2}-S_{p}{ }^{2} t_{\text {tab }}^{2} / n_{2}\right)=0
$$

Where, $a=\left(\bar{x}_{1}^{2}-S_{p}^{2} t^{2} / n_{1}\right), b=-2 \bar{x}_{1} \bar{x}_{2}, c=\left(\bar{x}_{2}{ }^{2}-S_{p}{ }^{2} t^{2} / n_{2}\right)$

The values of $\theta_{\mathrm{L}}$ and $\theta_{\mathrm{U}}$ of the confidence interval can be obtained as:

$$
\theta_{. t}=\frac{-b-\sqrt{\left(b^{2}-4 a c\right)}}{2 a} \quad \theta_{. u}=\frac{-b+\sqrt{\left(b^{2}-4 a c\right)}}{2 a}
$$

\section{Method Validation}

\section{Specificity and selectivity}

The ability of the method to determine accurately and specifically the analyte of interests in the presence of other components in a sample matrix (that may be expected to be present in the sample matrix) under the stated conditions of the test (specificity $=100 \%$ selectivity).

\section{Linearity}

The ability of the method to obtain test results proportional to the concentration of analyte. The linearity was determined by dividing the response with the respective concentrations and to plot these 'relative responses' as a function of the concentration, on a log scale. The line obtained should be horizontal over the full linear range, with a positive deviation at low concentrations and a negative deviation at high concentrations.

\section{Accuracy and precision}

The accuracy of an analytical method is the extent to which test results generated by the method and the true value agree. The precision of a method is the closeness of agreement between independent test results obtained under stipulated conditions. The accuracy and precision of the proposed method was evaluated within the linear dynamic range based on the analysis of flucloxacillin at 2.0, 5.0 and $8.0 \mu \mathrm{g} / \mathrm{mL}$. Five independent analyses were performed at each concentration level within one day (intra day precision) as well as for five consecutive days (inter day precision).

\section{Recovery studies}

The fraction of analyte added to the test sample (fortified or spiked) prior to analysis, which is measured by the method. Analytical methods aim to estimate the true value of the analyte concentration with an uncertainty that is fit for purpose. However, in such analytical methods, the analyte is transferred from the complex matrix to a simpler solution, whereby there is a loss of analyte. As a consequence, the measured value will be lower than the true 
concentration present in the original matrix. Therefore, assessing the efficiency of the method in detecting all of the analyte present is a part of the validation process. Recovery experiments were carried out by addition of excipients with the pure flucloxacillin. For this, $3.5 \mu \mathrm{g} / \mathrm{mL}$ of flucloxacillin solution $(1.0 \mu \mathrm{g} / \mathrm{mL})$ was transferred into a $10 \mathrm{~mL}$ volumetric flask followed by $2.0 \mu \mathrm{g} / \mathrm{mL}$ of excipients such as glucose, starch, fructose, lactose and magnesium stearate and the volume was completed up to the mark with methanol. The total amount was determined by using the corresponding regression equation.

\section{Limit of detection (LOD)}

The limit of detection is the point at which a measured value is larger than the uncertainty associated with it. It is the lowest concentration of analyte in a sample that can be detected but not necessary quantified.

$$
\mathrm{LOD}=3.3 \times \mathrm{S}_{\mathrm{O}} / \mathrm{b}
$$

Where $S_{O}$ and $b$ are standard deviation and slope of the calibration line, respectively.

\section{Limit of quantitation $(L O Q)$}

The lowest concentration or amount of analyte that can be determined quantitatively with an acceptable level of repeatability precision and trueness.

\section{Results and Discussion}

$$
\mathrm{LOQ}=10.0 \times \mathrm{S}_{\mathrm{O}} / \mathrm{b}
$$

\section{Reaction with $\sigma$-acceptor}

The absorption spectrum of iodine in dichloromethane showed only one peak with maximum absorption at $500 \mathrm{~nm}$. The color of iodine changes to yellow upon reaction with flucloxacillin. This is due to charge transfer complexation reaction of flucloxacillin and iodine. The absorption spectrum of flucloxacillin-iodine reaction product showed absorption peaks at 290 and $362 \mathrm{~nm}$ (Figure 1). The stoichiometry of the reaction was studied by Job's method of continuous variations. It was observed from the Figure 2 that the combining molar ratio between flucloxacillin-iodine is 1:1. It has been reported that the charge-transfer complex between drug and iodine ${ }^{7}$ would have an ionized structure $\mathrm{DI}^{+} \ldots \mathrm{I}_{3}^{-}$. The absorption spectrum of this charge-transfer complex is identical to that of $\mathrm{I}_{3}{ }^{-}$in dichloromethane as it also absorbed at $290 \mathrm{~nm}$ and $360 \mathrm{~nm}$. On the basis of our experimental findings and the literature background, the reaction mechanism is proposed and given in Scheme 1.

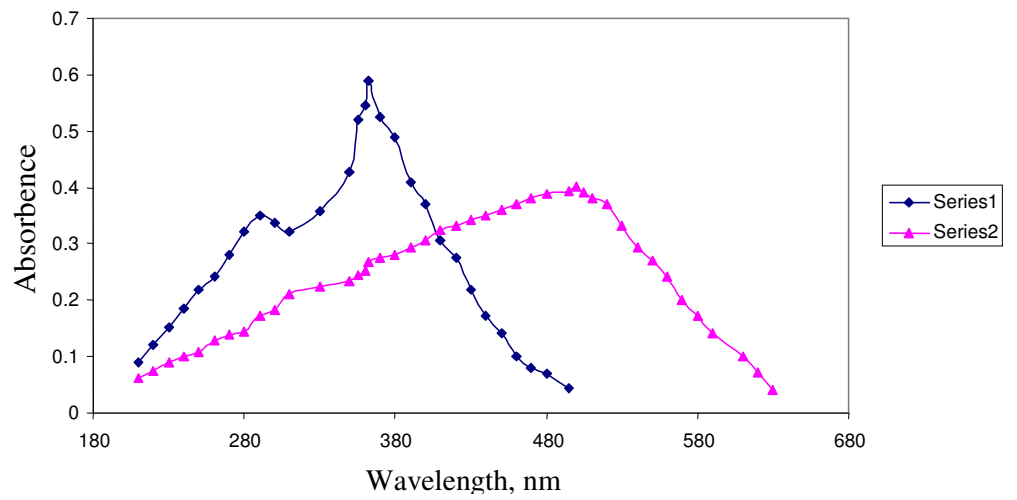

Figure 1. Absorption spectra of (1) Flucloxacillin $(9 \mu \mathrm{g})$ in methanol and iodine $1.0 \mathrm{~mL}$ of $0.1 \%$ in dichloromethane (2) Iodine $(1.0 \mathrm{~mL}$ of $0.1 \%)$ in dichloromethane in $10 \mathrm{~mL}$ volumetric flasks. 

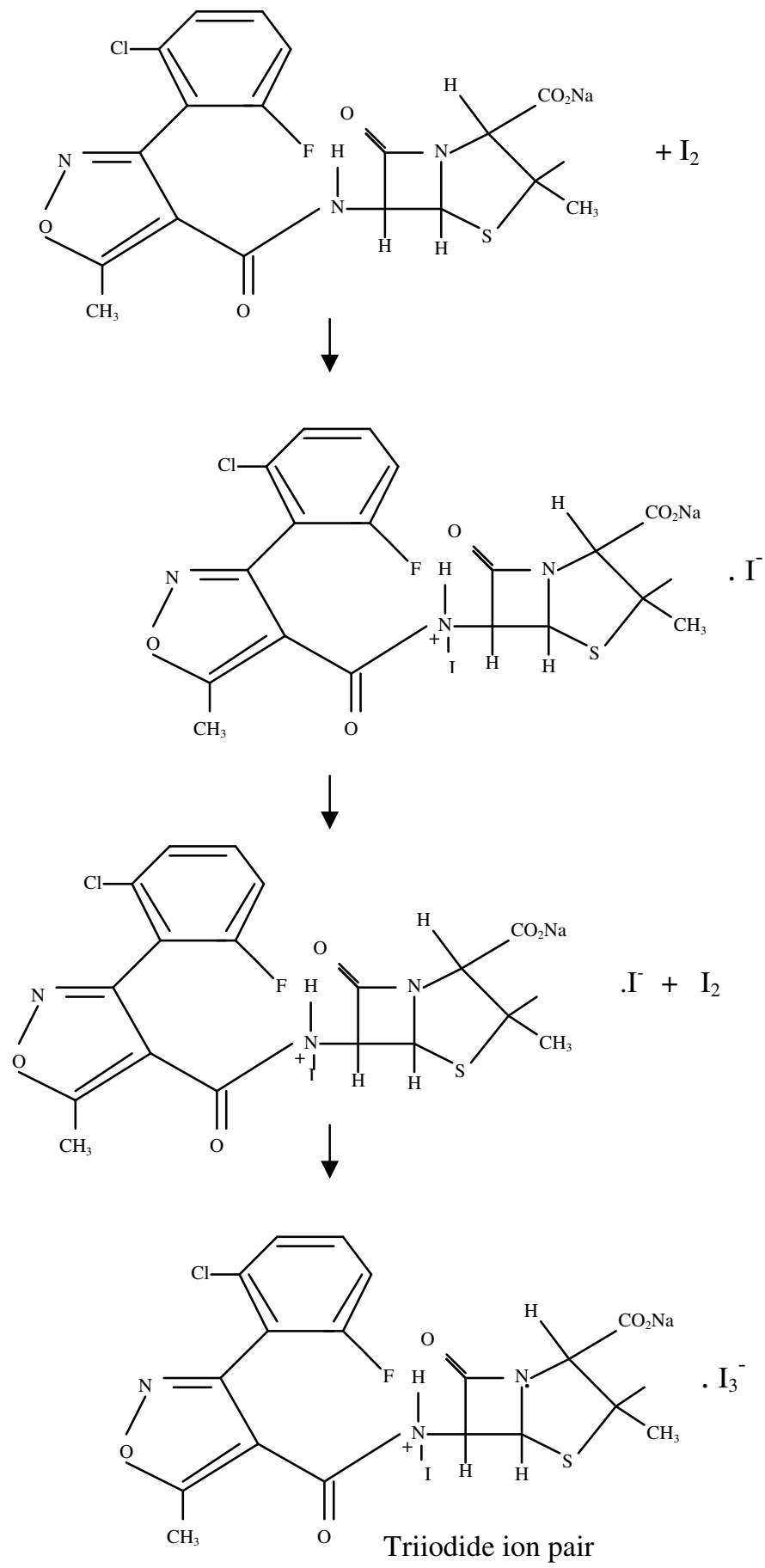

Scheme 1. 


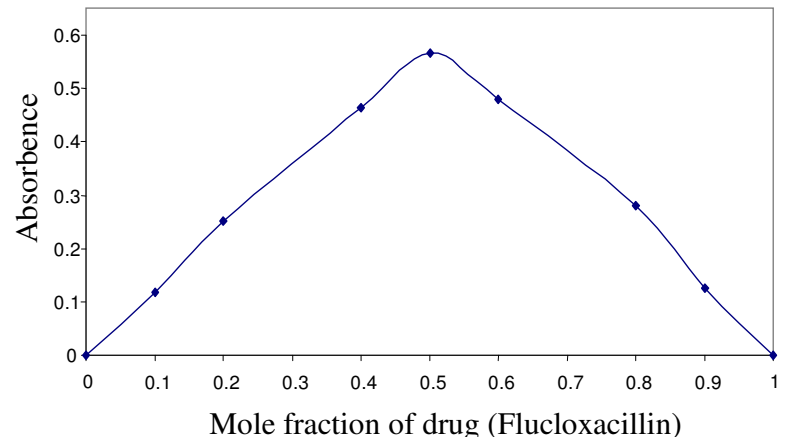

Figure 2. Jobs plot for stoichiometric ratio between flucloxacillin and iodine $\left(2.03 \times 10^{-4} \mathrm{M}\right.$ each). Optimizations of variables

The different parameters affecting the color development were extensively studied to determine the optimum conditions for the assay procedures. The optimum values of the variables were maintained throughout the determination process.

\section{Effect of reaction time}

The colored product was formed immediately and remained stable at room temperature for about $2 \mathrm{~h}$. The absorbance was measured after $3 \mathrm{~min}$. of mixing the reagent.

\section{Effect of iodine concentration}

In order to study the effect of the volume of $0.1 \%$ iodine on the absorbance of the charge transfer complex, varying volumes $(0.1-1.2 \mathrm{~mL})$ were treated, separately with $50 \mu \mathrm{g}$ of flucloxacillin. The results are shown in Figure 3 which indicated that $0.8 \mathrm{~mL}$ of $0.1 \%$ iodine gave the maximum absorbance and remained constant by further addition of iodine. Therefore, a volume of $1.0 \mathrm{~mL}$ was chosen as an optimum value for the determination.

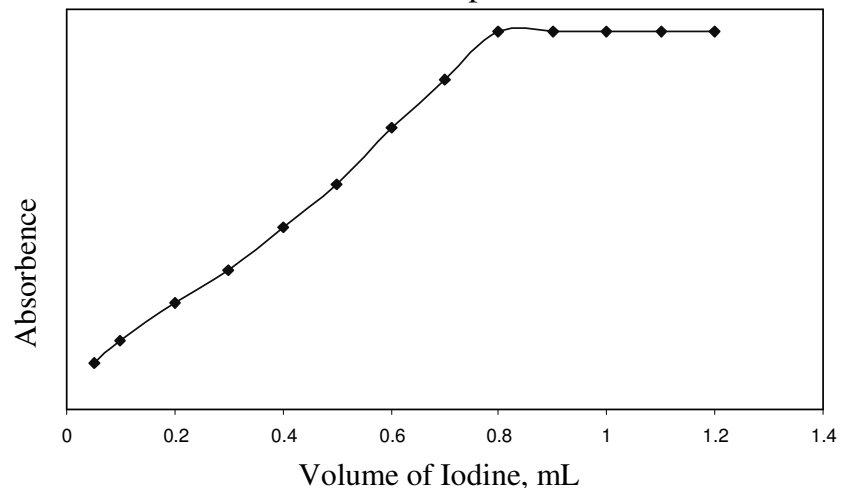

Figure 3. Effect of iodine concentraction; (Keeping constant $0.18 \mathrm{~mL}$ of $0.5 \mu \mathrm{g} / \mathrm{mL}$ flucloxacillin).

\section{Validation of the proposed method}

Under the optimum experimental conditions, the absorbance-concentration plot for the proposed method was found to be rectilinear over the range of $1-9 \mu \mathrm{g} / \mathrm{mL}$ (Figure 4). Linear regression analysis of calibration data gave the regression equation cited in Table 1 with correlation coefficient close to unity in both the cases. The suitability of the reaction products was estimated in the reaction mixture, it was found that the absorbance is stable for at least ten days at room temperature. 


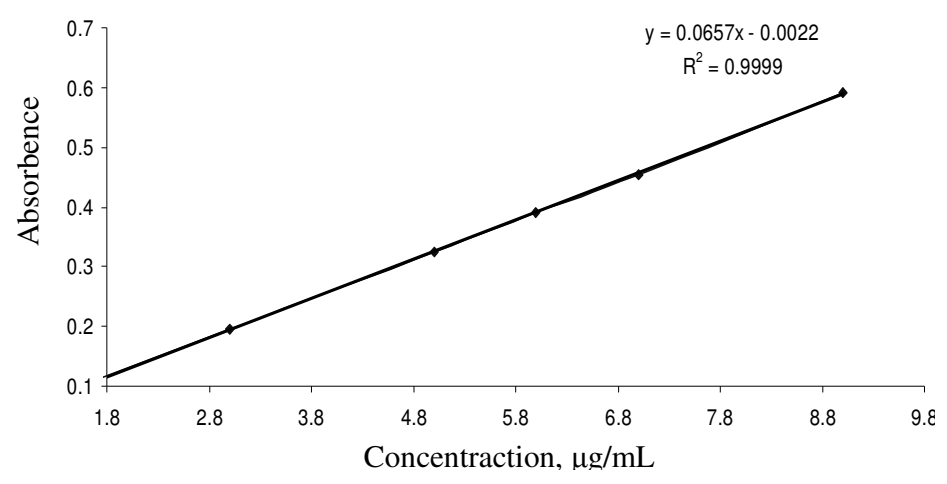

Figure 4. Linear regression equation of the proposed method.

Table 1. Summary of optical and regression characteristics of the proposed method.

\begin{tabular}{ll}
\hline \multicolumn{1}{c}{ Parameters } & \multicolumn{1}{c}{ Flucloxacillin } \\
\hline Linear dynamic range, $\mu \mathrm{g} / \mathrm{mL}_{\text {Regression equation }^{\mathrm{a}}}$ & $1.0-9.0$ \\
$\mathrm{~S}_{\mathrm{a}}$ & $\mathrm{Y}=6.57 \times 10^{-2}+2.2 \times 10^{-3} \mathrm{X}$ \\
$\mathrm{t} \mathrm{S}_{\mathrm{a}}{ }^{\mathrm{b}}$ & $9.16 \times 10^{-4}$ \\
$\mathrm{~S}_{\mathrm{b}}$ & $2.04 \times 10^{-3}$ \\
$\mathrm{t} \mathrm{S}_{\mathrm{b}}{ }^{\mathrm{b}}$ & $2.61 \times 10^{-4}$ \\
Correlation coefficient (r) & $5.84 \times 10^{-4}$ \\
$\mathrm{LOD}, \mu \mathrm{g} / \mathrm{mL}$ & 0.9999 \\
LOQ, $\mu \mathrm{g} / \mathrm{mL}$ & $2.47 \times 10^{-1}$ \\
Variance $\left(\mathrm{S}_{\mathrm{o}}{ }^{2}\right)$ of calibration line & $8.15 \times 10^{-2}$ \\
\hline
\end{tabular}

The working standard sample solutions were stressed by light and heat (up to $50{ }^{\circ} \mathrm{C}$ ) for $5 \mathrm{~h}$. It was observed that stress by such conditions did not cause significant degradation. There is no change in the absorption spectra. All stressed samples (light and heat) and unstressed sample solutions were analyzed for the active content of flucloxacillin, which gave acceptable recoveries of the drug. The influence of frequently encountered excipients on the proposed method was studied by adding different amounts of possible interferents to the sample. It was observed that glucose, fructose, sucrose, cellulose, starch, lactose, magnesium stearate and sodium stearyl fumarate did not interfere the proposed method.

The accuracy and precision of the proposed method was established by performing intraday and interday assays by determining the content of flucloxacillin samples at three different concentration levels (low, medium and high). These assays were investigated by measuring five independent analyses at $2,5 \& 8 \mu \mathrm{g} / \mathrm{mL}$ concentration levels within 1 day and on 5 consecutive days, respectively (Table 2). The standard deviation, relative standard deviation and standard analytical error obtained by both methods are acceptable i.e. within the permissible bias range and therefore can be considered to be satisfactory.

Recovery study was employed to check the validity of the proposed procedures. In this method, a known amount of excipients was added to its pure form at different concentration levels and the nominal value of the drug was calculated following the proposed procedure. The results are summarized in Table 3. 
Table 2. Summary of accuracy and precision results of the proposed method in pure form.

\begin{tabular}{ccccccc}
\hline \multirow{2}{*}{ Proposed methods } & \multicolumn{2}{c}{ Amount, $\mu \mathrm{g} / \mathrm{mL}$} & RSD & REC. & SAE $^{\mathrm{b}}$ & C.L. $^{\mathrm{c}}$ \\
\cline { 2 - 7 } Intra day assay & Taken & Found $\pm \mathrm{SD}^{\mathrm{a}}$ & $\%$ & & & \\
\hline & 2.00 & $1.999 \pm 0.003$ & 0.150 & 99.950 & $1.3 \times 10^{-3}$ & $3.7 \times 10^{-3}$ \\
& 5.00 & $5.001 \pm 0.005$ & 0.099 & 100.02 & $2.2 \times 10^{-3}$ & $6.2 \times 10^{-3}$ \\
\multirow{3}{*}{ Inter day assay } & 8.00 & $7.998 \pm 0.007$ & 0.088 & 99.975 & $3.1 \times 10^{-3}$ & $8.7 \times 10^{-3}$ \\
\hline & 2.00 & $1.999 \pm 0.005$ & 0.250 & 99.950 & $2.2 \times 10^{-3}$ & $6.2 \times 10^{-3}$ \\
& 5.00 & $4.998 \pm 0.008$ & 0.160 & 99.960 & $3.6 \times 10^{-3}$ & $9.9 \times 10^{-2}$ \\
& 8.00 & $8.001 \pm 0.010$ & 0.125 & 100.013 & $4.5 \times 10^{-3}$ & $1.2 \times 10^{-2}$ \\
\hline
\end{tabular}

${ }^{a}$ Mean for 5 independent analyses. ${ }^{b}$ SAE, standard analytical error. ${ }^{c}$ C.L., confidence limit at $95 \%$ confidence level and 4 degrees of freedom $(t=2.776)$

Table 3. Summary of accuracy and precision results of the proposed method after adding excipients.

\begin{tabular}{|c|c|c|c|c|c|c|}
\hline \multirow{2}{*}{ Excipients } & \multicolumn{2}{|c|}{ Amount, $\mu \mathrm{g} / \mathrm{mL}$} & \multirow{2}{*}{$\frac{\text { RSD }}{\%}$} & \multirow{2}{*}{ REC. } & \multirow{2}{*}{$\mathrm{SAE}^{\mathrm{b}}$} & \multirow{2}{*}{ C.L. ${ }^{c}$} \\
\hline & Taken & Found $\pm \mathrm{SD}^{\mathrm{a}}$ & & & & \\
\hline Glucose & $3 . .50$ & $3.498 \pm 0.006$ & 0.172 & 99.943 & 0.0027 & 0.0075 \\
\hline Fructose & $3 . .50$ & $3.499 \pm 0.010$ & 0.286 & 99.971 & 0.0045 & 0.0124 \\
\hline Cellulose & $3 . .50$ & $3.496 \pm 0.012$ & 0.343 & 99.886 & 0.0054 & 0.0149 \\
\hline Starch & $3 . .50$ & $3.502 \pm 0.008$ & 0.228 & 100.057 & 0.0036 & 0.0099 \\
\hline Lactose & $3 . .50$ & $3.497 \pm 0.011$ & 0.315 & 99.914 & 0.0049 & 0.0037 \\
\hline Magnesium Stearate & $3 . .50$ & $3.499 \pm 0.007$ & 0.200 & 99.971 & 0.0031 & 0.0075 \\
\hline
\end{tabular}

As can be seen from the Table 3 that recovery obtained by the proposed procedure is quite satisfactory with low RSD. The results of the proposed method were statistically compared with those of the developed reference method using point and interval hypothesis tests. Table 4 shows that the calculated ( $t$ - paired) and $F$-values at 95\% confidence level are less than the theoretical ones, confirming no significant difference between the methods compared. It can also be seen from Table 4 that the bias evaluated by interval hypothesis test is within the acceptable range of $\theta_{\mathrm{L}}=0.98$ and $\theta_{\mathrm{U}}=1.02$.

Table 4. Assay results of flucloxacillin using the proposed method and reference method ${ }^{8}$.

\begin{tabular}{ccc}
\hline Parameters & Proposed method & Reference method \\
\hline Recovery, \% & 99.988 & 99.954 \\
RSD & 0.185 & 0.397 \\
t & 0.48 & \\
F & 1.98 & \\
$\theta_{\mathrm{L}}$ & 0.983 & \\
$\theta_{\mathrm{U}}$ & 1.007 & \\
\hline
\end{tabular}

The proposed method was further extended to the in vitro determination of flucloxacillin in human urine samples. The results are summarized in Table 5. These results are satisfactorily accurate and precise. 
Table 5. Application of the proposed method to the determination of flucloxacillin in human urine samples.

\begin{tabular}{ccc}
\hline Amount added, $\mu \mathrm{g} / \mathrm{mL}$ & Amount found, $\mu \mathrm{g} / \mathrm{mL}$ & Recovery, $\%$ \\
\hline 1.0 & 0.9782 & 97.82 \\
2.0 & 1.9597 & 97.99 \\
3.0 & 2.9421 & 98.07 \\
4.0 & 3.9251 & 98.13 \\
5.0 & 4.9104 & 98.21 \\
6.0 & 5.9033 & 98.39 \\
7.0 & 6.8951 & 98.50 \\
8.0 & 7.9015 & 98.77 \\
9.0 & 8.9157 & 99.06 \\
$\bar{X}$ & & 98.33 \\
RSD & & 0.403 \\
\hline
\end{tabular}

\section{Conclusions}

The proposed method does not require any laborious clean up procedure before measurement. In addition, the method has wider linear dynamic range with good accuracy and precision. The method shows no interference from the common excipients and additives. This may help in analyzing affectivity of this drug in human beings during treatment. Therefore, it is concluded that the proposed method is simple, sensitive and rapid for the determination of flucloxacillin in bulk and in human urine samples.

\section{References}

1. Williams D A and Lemke T L, Foye's Principles of Medicinal Chemistry. $5^{\text {th }}$ Edn., Lippincott Williams \& Wilkins, 2002.

2. Palabiyik I and Onur F, Anal Lett., 2004, 37, 2125-2150.

3. Al-Ghannam S, Mikrochim Acta, 2002, 138, 29-32.

4. $\quad$ Mohamed A E I, Salem H and Maher E, Thai J Pharm Sci., 2007, 31, 9-27.

5. Hartmann C, Smeyers - Verbeke J, Peninckx W, Heyden Y V, Venkeerghen P and Massart D L, Anal Chem., 1995, 67, 4491-4499.

6. Canada Health Protection Branch, Drugs Directorate guidelines, Acceptable methods, Ministry of National Health and Welfare, Draft, Ottawa, Canada, 1992.

7. Darwish I A, Anal Chim Acta, 2005, 549, 212- 220.

8. The British Pharmacopoeia, Vol I, Her Majesty Office, London, UK, 2009, 862. 


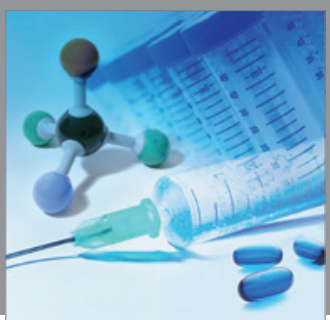

International Journal of

Medicinal Chemistry

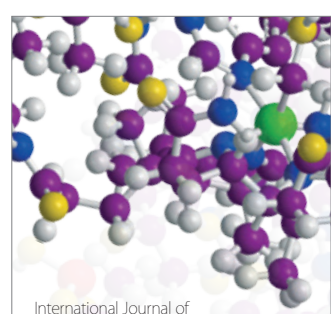

Carbohydrate Chemistry

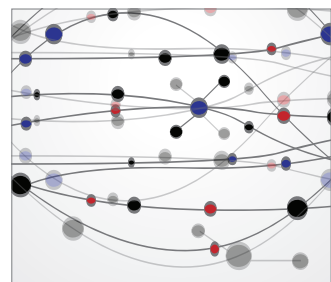

The Scientific World Journal
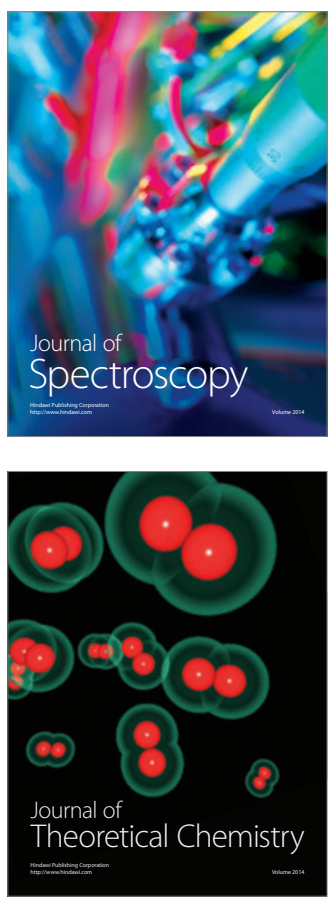
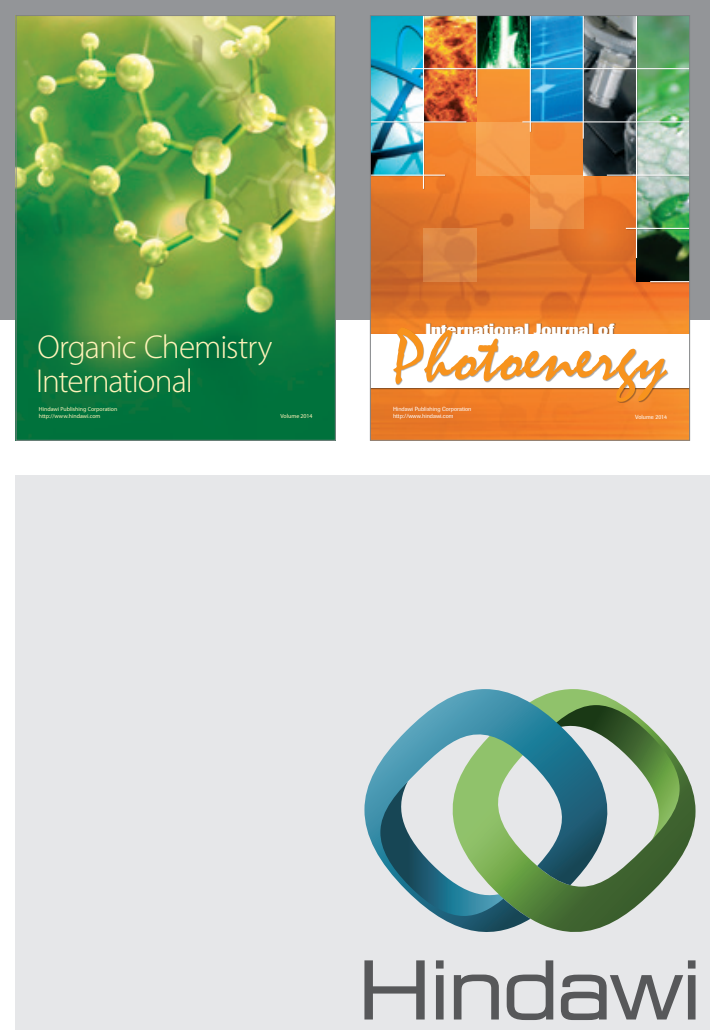

Submit your manuscripts at

http://www.hindawi.com
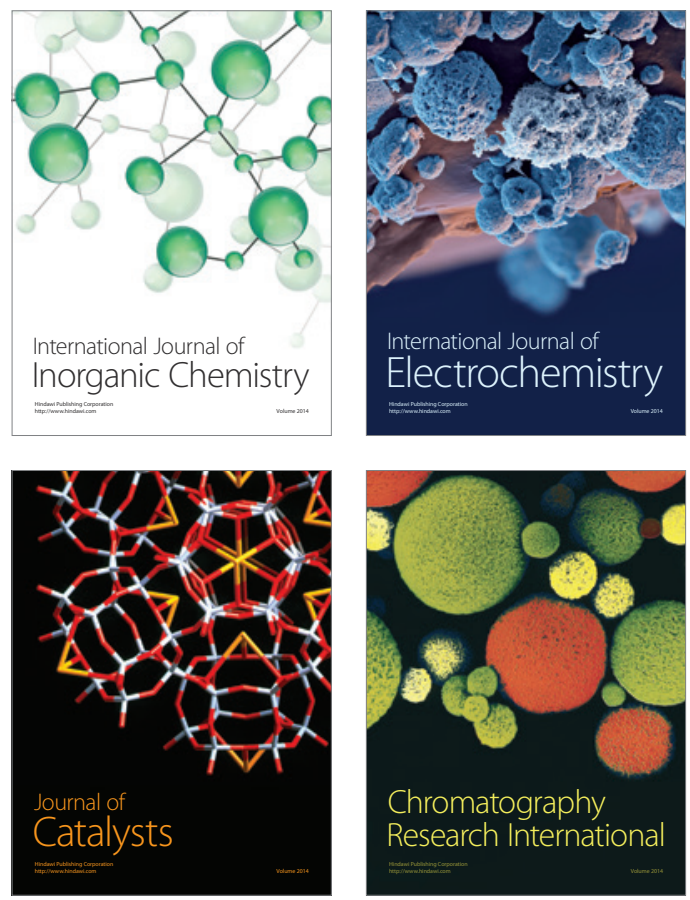
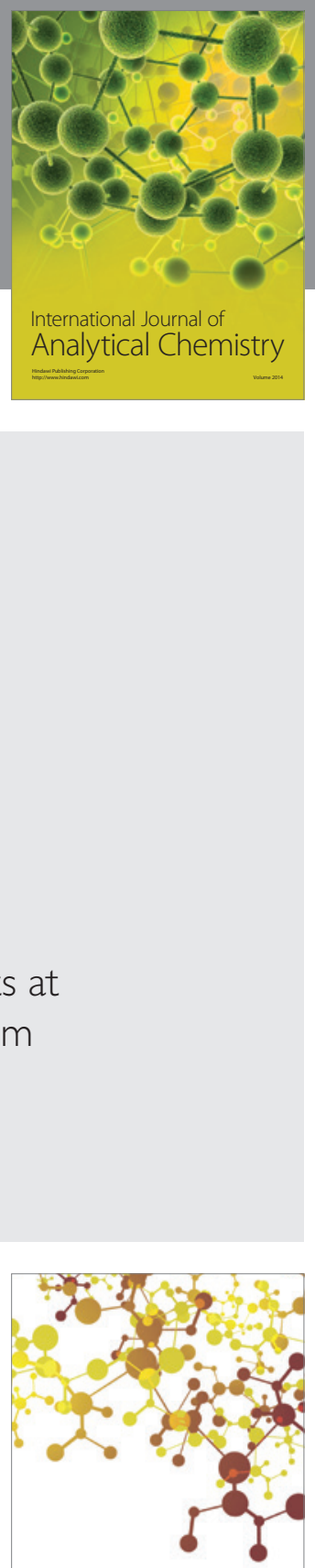

Journal of

Applied Chemistry
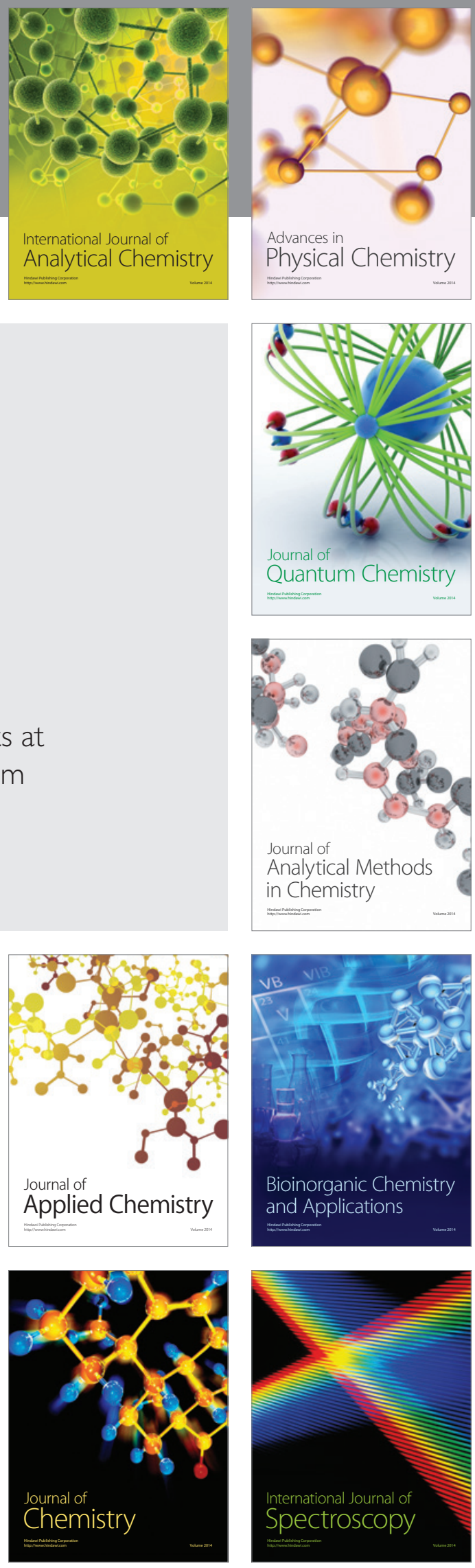